\title{
Antimicrobial Activity of Aqueous Garlic Extract (Allium sativum) Against Porphyro- monas gingivalis: An In-Vitro Study
}

\author{
S Alirezaei ${ }^{1}$, H Godarzi ${ }^{2}$, N Moezi ghadim *3, A Maheri ${ }^{4}$ \\ 1- Assistant professor, Oral Medecine Dept, faculty of Dentistry, Tehran medical sciences, Islamic Azad University, Tehran, Iran \\ 2- microbiology department medicin factuly-shahid beheshti university of medical sciences, tehran \\ 3- Assistant professor, Oral Medecine Dept, Member ship of Dental Material Research Center, Faculty of Dentistry,Tehran med- \\ ical sciences, Islamic Azad University, Tehran, Iran. \\ 4- Dentist, Islamic Azad University, Tehran, Iran
}

\begin{tabular}{l}
\hline ARTICLE INFO \\
\hline Article History \\
Received: May 2019 \\
Accepted: Apr 2019 \\
ePublished: Jun 2019 \\
Corresponding author: \\
Assistant professor, \\
Oral Medecine Dept, \\
faculty of Dentistry,Teh- \\
ran medical sciences, \\
Islamic Azad University, \\
Tehran, Iran \\
N Moezi ghadim \\
Email: nahid_mz_g@, \\
yahoo.com
\end{tabular}

\begin{abstract}
Background and Aim: Oral hygiene is important against the development of chronic periodontitis. There are concerns about bacterial resistance to antibiotics. The current study aimed to determine the antimicrobial activity of aqueous garlic extract (Allium sativum) against Porphyromonas gingivalis ( $\mathrm{P}$. gingivalis).

Materials and Methods:Aqueous garlic extract was prepared, and the inhibitory effect of the extract was tested against P. gingivalis. The minimum inhibitory concentration (MIC) and the minimum bactericidal concentration (MBC) against the control group $(0.2 \%$ chlorhexidine) were also determined.

Result: Significant differences were observed concerning the MIC $(1.21 \pm 0.37 \mu \mathrm{l})$ and $\operatorname{MBC}(1.44 \pm 0.67 \mu \mathrm{l})$ against $\mathrm{P}$. gingivalis between the aqueous garlic extract and control groups $(0.29 \pm 0.1 \mu \mathrm{l} ; \mathrm{P}<0.001)$. There was a significant difference in the inhibitory zone against $\mathrm{P}$. gingivalis between the aqueous garlic extract group $(20.1 \pm 1.4 \mathrm{~mm})$ and the control group $(27.3 \pm 1.8 \mathrm{~mm})$; the inhibitory zone was larger in the control group $(\mathrm{P}<0.000)$.

Conclusion: The results suggested that although chlorhexidine exhibited better antimicrobial activity against $\mathrm{P}$. gingivalis, the aqueous garlic extract also showed acceptable results. Further research using different extraction methods and concentrations is suggested.

Keywords: Microbial Sensitivity Tests, Plant Extracts, Garlic, Porphyromonas gingivalis
\end{abstract}

J Res Dent maxillofac Sci 2019;4(4):17-22

DOI: $10.29252 / j r d m s .4 .4 .17$

\section{Introduction:}

The accumulation of bacterial plaque at gingival margins is the primary etiological factor in the development of chronic periodontitis. ${ }^{(1)}$ The oral cavity is inhabited by different bacterial species. Supragingival plaque shows the accumulation of Gram-positive cocci while subgingival plaque mainly comprises Aggregatibacter actinomycetemcomitans (Aa),
Prevotella intermedia, Porphyromonas gingivalis (P. gingivalis), Tannerella forsythia, and Fusobacterium. ${ }^{(2)} \mathrm{P}$. gingivalis is an important Gram-negative anaerobe oral bacterium, which is considered one of the major etiological factors in progressive periodontitis. ${ }^{(3)}$ Reduction of the bacterial load and mechanical methods for the removal of plaque are the 
main current treatments for gingivitis and periodontitis. $^{(4)}$

Although mechanical treatment decreases subgingival microorganisms, it is not able to eliminate all pathogens. Systemic antibiotics can be used with conventional therapy to delay bacterial proliferation; however, their prolonged use can lead to the development of resistant strains. ${ }^{(5)}$ There is significant interest in finding new antibacterial agents considering the increased bacterial resistance to antibiotics. ${ }^{(6)}$

The Allium is the main representative genus of the Alliaceae family that is mostly cultivated in the northern hemisphere. Since ancient times, garlic (Allium sativum L.) has been used as a common remedy for many diseases. The first citation of this plant can be found in the Codex Ebers (1550 BC), which is an Egyptian medical papyrus that has reported numerous therapeutic effects of garlic, including antidiabetic, anti-atherosclerotic, anti-thrombotic, anti-hypertensive, anti-hyperlipidemic, anti-inflammatory, antioxidant, and anticancer activities. ${ }^{(7,8)}$ There has been increasing awareness of garlic medicinal properties. Several reports have suggested that garlic is a rich source of flavonoids and sulfur-containing compounds that have antimicrobial and antioxidant properties. ${ }^{(9)}$ Garlic has been documented as a valuable spice and a popular medicine for various disorders. ${ }^{(8)}$ Garlic is a strong antibacterial agent and inhibits both Gram-positive and Gram-negative bacteria, including Escherichia, Salmonella, Streptococcus mutans (S. mutans), P. gingivalis, Staphylococcus, Klebsiella, Proteus, and Helicobacter pylori. ${ }^{(10-13)}$

Allicin, which is a volatile molecule, is one of the main ingredients of freshly crushed garlic. It causes the pungent smell of garlic and is a chemically unstable molecule. ${ }^{(10)}$ It is reported that aqueous extract of garlic $(25,50$, and $75 \mu \mathrm{l})$ has shown 16-, 20-, and 25-mm zones of inhibition against $\mathrm{P}$. gingivalis, respectively. ${ }^{(1)}$ The garlic extract $(57.1 \%(\mathrm{w} / \mathrm{v})$ containing $220 \mathrm{mg} /$ $\mathrm{ml}$ of allicin) inhibits the growth of $\mathrm{P}$. gingivalis. Garlic extract also inhibits the trypsin-like $(92.7 \%)$ and total protease activity $(94.88 \%)$ of P. gingivalis. ${ }^{(14)}$ It has been suggested that the de- velopment of resistance to allicin is more difficult compared to certain antibiotics. ${ }^{(14)}$ Therefore, the current study aimed to determine the antimicrobial activity of aqueous garlic extract (Allium sativum) against $\mathrm{P}$. gingivalis.

\section{Materials and Methods}

This in-vitro experimental study was performed to examine the antimicrobial effect of aqueous garlic extract (Allium sativum) on P. gingivalis.

Garlic bulbs from the Northern region of Iran were dried at room temperature far from sunlight seven months after being harvested. Garlic powder $(10 \mathrm{~g})$ was blended in $100 \mathrm{ml}$ of distilled water filtered using cotton wool and ultra-filtered under reduced pressure using a Buchner funnel and a side-arm flask. By subtracting the weight of insoluble material from the weight of the original cloves, the final concentration of garlic extract in the solution was determined to be $16.5 \%(\mathrm{w} / \mathrm{v})$. The garlic extract was stored at $-20^{\circ} \mathrm{C}$ and used for antibacterial testing. ${ }^{(3)}$

Bacterial culture:

P. gingivalis (ATCC 33277) was purchased from the Microbiology Center of Shahid Beheshti University of Medical Sciences, Tehran, Iran. Bacterial suspensions were prepared $(0.5 \mathrm{Mc}-$ Farland), and $100 \mu \mathrm{l}$ of each bacterial vial was added to $5 \mathrm{ml}$ of sterilized Brain Heart Infusion (BHI) broth and incubated at $37^{\circ} \mathrm{C}$ for 18 hours. After adjusting the cell concentration to an optical density (OD) equal to seven $\left[1.5 \times 10^{8}\right.$ colonyforming units $(\mathrm{CFU}) / \mathrm{ml}$ ], $50 \mu \mathrm{l}$ of this suspension was added to each well. ${ }^{(3)}$

Minimum inhibitory concentration (MIC): This study comprises two groups: garlic aqueous extract (case group, $\mathrm{n}=10$ ) and chlorhexidine (control group, $\mathrm{n}=10$ ). One $\mathrm{ml}$ of the standard bacterial suspension was mixed with $60 \mathrm{ml}$ of sterile Müller-Hinton agar medium and poured into Petri dishes. The agars were left to set, and each of the plate cups (10-mm diameter) were cut using a sterile cork borer, and agar discs were removed. Garlic extracts were prepared in a series of increasing concentrations. 
The bottom of each plate was marked off into eight segments. The procedure involved preparing two-fold dilutions of the antimicrobial agent. Serial dilution from $100 \%, 50 \%, 25 \%$, and $12.5 \%$ to $10 \%$ was used. Fifty $\mu$ l of extracted garlic was introduced into the wells using automatic microliter pipettes, and all plates were incubated at $37^{\circ} \mathrm{C}$ for 24 hours. A liquid growth medium was poured into tubes to a minimum volume of $2 \mathrm{ml}$ (macrodilution) or smaller volumes (microdilution) in a 96-well plate. Then, each tube or well was inoculated with a microbial inoculum prepared in the same medium after dilution of the standardized microbial suspension $(0.5 \mathrm{Mc}-$ Farland). After mixing, the inoculated tubes and the 96-well plate were incubated. Chlorhexidine (0.2\%; C9394, Sigma-Aldrich Inc., Missouri, USA) was used as a positive control. The negative control was distilled water. The sensitivity of $\mathrm{P}$. gingivalis and the control was determined by measuring the diameter $(\mathrm{mm})$ of the zone of inhibition. The MIC is the lowest concentration of the antimicrobial agent that completely inhibits bacterial growth. ${ }^{(11)}$

Minimum bactericidal concentration (MBC): To determine the $\mathrm{MBC}$, the MIC dilution tubes with no growth along with the control tube were subcultured and anaerobically incubated for 24 hours at $37^{\circ} \mathrm{C}$. The colonies were counted on the next day. The microorganism growth in the control tube was compared to that in the MIC test tubes. A similar number of colonies indicated bacteriostatic activity while a reduced number of colonies indicated a partial or slow bactericidal activity. If there is no microorganism growth, the garlic extract is known to have a bactericidal effect. However, the garlic extract is known to have no bacteriostatic effect if microorganism growth is detected. ${ }^{(1)}$

Statistical analysis:

The data were analyzed using t-test $(\mathrm{P}<0.05)$.

\section{Result:}

The MIC and MBC of aqueous garlic extract against $\mathrm{P}$. gingivalis are presented in Table 1 . According to the results, significant differences were observed regarding MIC $(1.21 \pm 0.37 \mu 1)$ and MBC $(1.44 \pm 0.67 \mu 1)$ between the aqueous garlic extract and chlorhexidine groups $(0.29 \pm 0.1 \mu \mathrm{l})$ against $\mathrm{P}$. gingivalis $(\mathrm{P}<0.001)$.
Table 1. Minimum bactericidal concentration (MIC) and minimum bactericidal concentration (MBC) of aqueous garlic extract against Porphyromonas gingivalis ( $\mathrm{P}$. gingivalis)

\begin{tabular}{lccc}
\hline \multicolumn{1}{c}{ Groups } & & Mean \pm SD & CV (\%) \\
\hline $\begin{array}{l}\text { Aqueous garlic } \\
\text { extract }\end{array}$ & $\mathrm{MIC}(\mu \mathrm{g} / \mathrm{ml} ; \mathrm{n}=10)$ & $1.21 \pm 0.37$ & 30 \\
\cline { 2 - 4 } & $\mathrm{MBC}(\mu \mathrm{g} / \mathrm{ml})$ & $1.44 \pm 0.67$ & 46 \\
\hline Chlorhexidine & $\mathrm{MIC}(\mu \mathrm{g} / \mathrm{ml} ; \mathrm{n}=10)$ & $0.29 \pm 0.1$ & \\
\hline P-value & & & \\
\hline
\end{tabular}

$\mathrm{SD}=$ Standard Deviation, $\mathrm{CV}=$ Coefficient of Variation

There was a significant difference in the inhibitory zone against $\mathrm{P}$. gingivalis between the aqueous garlic extract $(20.1 \pm 1.4 \mathrm{~mm})$ and chlorhexidine $(27.3 \pm 1.8 \mathrm{~mm})$ groups; the inhibitory zone was greater in the chlorhexidine group $(\mathrm{P}<0.000$; Table 2).

Table 2. Inhibitory zone (mm) of aqueous garlic extract against Porphyromonas gingivalis ( $P$. gingivalis)

\begin{tabular}{ccc}
\hline Groups & Mean \pm SD & CV (\%) \\
\hline Aqueous garlic extract $(\mathrm{n}=10)$ & $20.1 \pm 1.4$ & 6 \\
\hline Chlorhexidine $(\mathrm{n}=10)$ & $27.3 \pm 1.8$ & 7 \\
\hline P-value & & \\
\hline
\end{tabular}

$\mathrm{SD}=$ Standard Deviation, $\mathrm{CV}=$ Coefficient of Variation

\section{Discussion:}

Allium sativum, as a medical plant, exhibits antibacterial, antifungal, antiviral, and antiprotozoal effects, thereby acting as a natural antibiotic. ${ }^{(12-17)}$ However, few studies have attempted to determine its role in periodontitis.

In the current study, we tried to determine the antimicrobial activity of aqueous garlic extract (Allium sativum) against P. gingivalis. According to the results, significant differences were observed regarding the MIC $(1.21 \pm 0.37$ $\mu 1)$ and $\mathrm{MBC}(1.44 \pm 0.67 \mu \mathrm{l})$ between the aqueous garlic extract and chlorhexidine groups 


\section{$(0.29 \pm 0.1 \mu 1)$ against $\mathrm{P}$. gingivalis $(\mathrm{P}<0.001)$.}

There was a significant difference in the inhibitory zone against $\mathrm{P}$. gingivalis between the aqueous garlic extract $(20.1 \pm 1.4 \mathrm{~mm})$ and chlorhexidine groups $(27.3 \pm 1.8 \mathrm{~mm})$; the inhibitory zone was larger in the chlorhexidine group $(\mathrm{P}<0.000)$. Numerous garlic extract preparation techniques have been shown to exhibit a wide spectrum of antibacterial activity against clinical isolates of Gram-negative, Gram-positive, and acid-fast bacteria. Essential oils of garlic bulbs have antimicrobial activity against Staphylococcus aureus (S. aureus), Pseudomonas aeruginosa (P. aeruginosa), and Escherichia coli with inhibition zones of $14.8,21.1$, and $11.0 \mathrm{~mm}$, respectively. ${ }^{(12)}$ Our results were dissimilar to this report; differences might be related to bacterial strains. It seems that the extraction method affects the antimicrobial activity of the obtained extract. It is reported that aqueous extracts of garlic $(25,50$, and $75 \mu \mathrm{l})$ have caused 16-, 20-, and 25-mm zones of inhibition, respectively, against P. gingivalis. ${ }^{(1)}$ Our result was similar to this report.

Different concentrations of garlic extract (5, 10,20 , and $100 \%$ ) have similar effects against S. mutans, Streptococcus sanguis (S. sanguis), Streptococcus salivarius (S. salivarius), P. aeruginosa, and lactobacillus spp. ${ }^{(13)}$ In the evaluation of the inhibitory effect of garlic against $\mathrm{P}$. gingivalis and $\mathrm{Aa}$, it has been revealed that garlic extract may have therapeutic effects on periodontitis $^{(1)}$. Aqueous garlic extract did not show any inhibition zone against Aa in the well diffusion method but it showed inhibitory activity against Aa. This difference may be related to the binding of constituents of garlic to those of the agar medium, thereby limiting the diffusion. Therefore, the MIC obtained using the broth dilution method is considered more reliable. ${ }^{(18)}$ In addition, the MIC for Aa was $125 \mu \mathrm{l} / \mathrm{ml}$, which was much higher than the concentration used for well diffusion $(25,50$, and $75 \mu \mathrm{l} / \mathrm{ml})$, which may have swayed the results related to the inhibitory effect of garlic on $\mathrm{Aa}^{(18)}$ Of the Gram-negative species tested in the cited study, Leptotrichia buccalis (L. buccalis) was the least sensitive to garlic, with a MIC of $35.7 \mathrm{mg} / \mathrm{ml}$, which approached the MICs of the oral Gram-positive species. Although L. buccalis has a Gram-negative cell wall structure, it also possesses membranous, scale-like folds that cover its external surface. ${ }^{(19)}$ In the assessment of the antibacterial effect of garlic extract on erythromycin- and methicillin-resistant bacteria isolated from an operating room, Ataee et al reported that 70 strains $(100 \%)$ in the agar well diffusion method were sensitive to $4-12 \mu \mathrm{g} / \mathrm{ml}$ of garlic extract $(\mathrm{MIC}=8 \mu \mathrm{g} / \mathrm{ml}){ }^{(3)}$ In addition, the antibacterial effect of garlic extract has been reported against $S$. aureus strains in hamburgers. ${ }^{(19)}$ It is reported that the inhibition zones of different concentrations of garlic extract were not significantly different for S. mutans, S. sanguis, S. salivarius, $\mathrm{P}$. aeruginosa, and lactobacillus spp. Additionally, the inhibition zones of $5 \%, 10 \%$, and $20 \%$ concentrations were not significantly different. ${ }^{(20)}$ Similar results were found in our study. Aqueous extract $(16.5 \%)$ at serial dilution (10, $12.5,25,50$, and $100 \%$ ) exhibited no significant difference with $0.2 \%$ chlorhexidine gluconate. ${ }^{(17)}$ The MIC of the aqueous extracts of garlic in the cited study was $10 \%$. ${ }^{(17)}$

The main antimicrobial ingredient of garlic is an oxygenated sulfur compound, thio-2-. propene-1-sulfinic acid Sallyl ester, which is known as allicin. ${ }^{(16)}$ Several bacterial strains are sensitive to pure allicin. ${ }^{(16)}$ When the garlic is crushed, allicin is formed rapidly by the action of the alliinase (alliin lyase; EC 4.4.1.4) on alliin (S-allyl1-cysteine sulphoxide). ${ }^{(14)}$ Allicin reacts with free thiol groups; its key mechanism of antimicrobial activity is through interaction with thiol-containing enzymes, such as cysteine proteases and alcohol dehydrogenases. ${ }^{(14)}$ Since these enzymes are necessary for bacterial nutrition and metabolism, it has been suggested that the development of resistance to allicin is more difficult compared to certain antibiotics. ${ }^{(14)}$

Mouthwashes containing garlic extract have good in-vivo antibacterial activity against salivary S. mutans. ${ }^{(15)}$ Garlic extract mouthwash inhibits the formation of biofilms by Staphylococcus epidermidis at lower MIC levels. ${ }^{(15)}$ Allicin complexes with blood proteins and reduces bleeding at periodontal sites. ${ }^{(14)}$

Extensive use of antibiotics has led to antibiotic resistance; therefore, alternative agents that are effective against pathogens but do not disturb the normal flora are of particular interest. ${ }^{(16)}$ 
Aqueous garlic extract has antibacterial activity at room temperature. Garlic extract could be stored at $4^{\circ} \mathrm{C}$. Excessive warming should be avoided. ${ }^{(21)}$ This heat stability is very useful when the antimicrobial peptides are used as a food preservative. ${ }^{(21)}$ It seems that garlic extract contains antibacterial peptides or proteins, which show stable antibacterial activity at high temperatures less than $80^{\circ} \mathrm{C}$ with a broad antimicrobial spectrum. ${ }^{(21)}$

An investigation has shown the effect of aqueous garlic extract on Candida albicans (C. albicans) in the mouth. ${ }^{(22)}$

The results of the cited study showed that the aqueous extract of garlic was able to inhibit the growth of C. albicans but its effect was less than that of nystatin. ${ }^{(22)}$ Further research using different extraction methods and concentrations is suggested

\section{Conclusion:}

The results suggested that although chlorhexidine exhibited better antimicrobial activity against $\mathrm{P}$. gingivalis, the aqueous garlic extract also showed acceptable results. Garlic seems to be safe with the potential for broader applications.

\section{References:}

1. Shetty S, Thomas B, Shetty V, Bhandary R, Shetty RM. An in-vitro evaluation of the efficacy of garlic extract as an antimicrobial agent on periodontal pathogens: A microbiological study. Ayu. 2013 Oct;34(4):445-51.

2. Mageed MJ, Saliem Saif S. Antimicrobial effects of green tea extracts on Porphyromonas Gingivalis (in vitro study). J Dent Med Sci. 2015 Oct;14(10):33-39.

3. Ataee RA, Araqizade H, Yoosefi R, Mehrabi Tavana A, Ataee MH. Effect of Allium sativum Extract on Erythromycin and Methicillin Resistant Bacteria Isolated from Hospital Operating Room. J Med Bacteriol. 2016;5(1-2):7-14.

4. Saha SK, Saha S, Hossain MA, Paul SK. In vitro assessment of antibacterial effect of garlic (allium sativum) extracts on pseudomonas aeruginosa. Mymensingh Med J. 2015 Apr;24(2):22232.

5. Gull I, Saeed M, Shaukat H, Aslam MS, Samra ZQ, Athar AM. Inhibitory effect of Allium sativum and Zingiber officinale extracts on clinically important drug resistant pathogenic bacteria. Ann Clin Microbiol Antimicrob. 2012 Apr 27;11:8.

6. Viswanathan V, Phadatare AG, Mukne A. Antimycobacterial and Antibacterial Activity of Allium sativum Bulbs. Indian J Pharm Sci. 2014 May;76(3):256-61.

7. Bozcuk H, Ozdoğan M, Aykurt O, Topcuoğlu F, Ozturk H, Ekinci D, et al. Urginea maritima (L.) Baker (Liliaceae) extract induces more cytotoxicity than standard chemotherapeutics in the A549 non-small cell lung cancer (NSCLC) cell line. Turk J Med Sci. 2011;41(1):101-108.

8. Khaki A, Farnam A, Badie AD, Nikniaz H. Treatment Effects of Onion (Allium cepa) and Ginger (Zingiber officinale) on Sexual Behavior of Rat after Inducing an Antiepileptic Drug (lamotrigine). Balkan Med J. 2012 Sep;29(3):236-42. 9. Asadpour R, Azari M, Hejazi M, Tayefi H, Zaboli N. Protective effects of garlic aquous extract (Allium sativum), vitamin $\mathrm{E}$, and $\mathrm{N}$ acetylcysteine on reproductive quality of male rats exposed to lead. Vet Res Forum. $2013 \mathrm{Au}-$ tumn;4(4):251- 257.

10.Jabar MA, Al-Mossawi A. Susceptibility of some multiple resistant bacteria to garlic extract. Afr J Biotechnol. 2007;6(6):771-6.

11. Balouiri M, Sadiki M, Ibnsouda SK. Methods for in vitro evaluating antimicrobial activity: A review. J Pharm Anal. 2016 Apr;6(2):71-79.

12.Casella S, Leonardi M, Melai B, Fratini F, Pistelli L. The role of diallyl sulfides and dipropyl sulfides in the in vitro antimicrobial activity of the essential oil of garlic, Allium sativum L., and leek, Allium porrum L. Phytother Res. 2013 Mar;27(3):380-3.

13. Houshmand B, Mahjour F, Dianat O. Antibacterial effect of different concentrations of garlic (Allium sativum) extract on dental plaque bacteria. Indian J Dent Res. 2013 Jan-Feb;24(1):71-5. 14.Bakri IM, Douglas CW. Inhibitory effect of garlic extract on oral bacteria. Arch Oral Biol. $2005 \mathrm{Jul} ; 50(7): 645-51$.

15.Groppo FC, Ramacciato JC, Simões RP, Flório FM, Sartoratto A. Antimicrobial activity of garlic, tea tree oil, and chlorhexidine against oral microorganisms. Int Dent J. 2002 Dec;52(6):4337.

16. Borlinghaus J, Albrecht F, Gruhlke MC, Nwachukwu ID, Slusarenko AJ. Allicin: chemistry and biological properties. Molecules. 2014 Aug 
19;19(8):12591-618.

17. Mohamed AF, Elnima EI, Ghandour IA. Inhibitory Effect of Garlic Extract on Porphyromonas Gingivalis Isolated from Sudanese Aggressive Periodontitis Patients Compared to Chlorhexidine Digluconate $0.2 \%$. J Chem Pharm Res. 2017;9(4):259-263

18.Listgarten MA, Lai CH. Unusual cell wall ultrastructure of Leptotrichia buccalis. J Bacteriol. 1975 Aug;123(2):747-9.

19. Mozaffari Nejad AS, Shabani S, Bayat M, Hosseini SE. Antibacterial Effect of Garlic Aqueous Extract on Staphylococcus aureus in Hamburger. Jundishapur J Microbiol. 2014 Nov;7(11):e13134.

20.Karuppiah P, Rajaram S. Antibacterial effect of Allium sativum cloves and Zingiber officinale rhizomes against multiple-drug resistant clinical pathogens. Asian Pac J Trop Biomed. 2012 Aug;2(8):597-601.

21.Belguith $\mathrm{H}$, Kthiri F, Chati A, Abu Sofah A, Ben Hamida A, Landoulsi A. Study of the effect of aqueous garlic extract (Allium sativum) on some Salmonella serovars isolates. Emir J Food Agric. 2010;22(3):189-206

22.Haji Fattahi F, Alirezaei S, Goodarzi H, Lesan L, Khalesi MA. Investigation of antifungal effect of aqueous extract of garlic on Candida albicans (INVITRO). J Res Dent Sci. 2019 Spring;16(1):20-26.

Please cite this paper as:

Alirezaei S, Godarzi H, Moezi ghadim N, Maheri A. Antimicrobial Activity of Aqueous Garlic Extract (Allium sativum) Against Porphyromonas gingivalis: An In-Vitro Study. J Res Dentomaxillofac Sci. 2019; 4 (4) :17-22 